\title{
Comparing Pre-Service Teachers' Attitudes toward Inclusive Education in Thailand and Japan
}

\author{
Akihiro Nishio ${ }^{1}$, Jiraporn Chano², Yoshitaka Suzuki ${ }^{3}$, Naotaka Iketani ${ }^{3}$ \\ ${ }^{1}$ Health Administration Center, Gifu University, Gifu, Japan \\ ${ }^{2}$ Faculty of Education, Mahasarakham University, Mahasarakham, Thailand \\ ${ }^{3}$ Faculty of Education, Graduate School of Education, Gifu University, Gifu, Japan \\ Email: ^a_nishio@gifu-u.ac.jp
}

How to cite this paper: Nishio, A., Chano, J., Suzuki, Y., \& Iketani, N. (2020). Comparing Pre-Service Teachers' Attitudes toward Inclusive Education in Thailand and Japan. Creative Education, 11, 2096-2105. https://doi.org/10.4236/ce.2020.1110152

Received: September 25, 2020

Accepted: October 24, 2020

Published: October 27, 2020

Copyright (c) 2020 by author(s) and Scientific Research Publishing Inc. This work is licensed under the Creative Commons Attribution International License (CC BY 4.0).

http://creativecommons.org/licenses/by/4.0/ (c) (i) Open Access

\begin{abstract}
Background: Several studies have shown that classroom teachers can strongly influence the implementation and potential success of inclusive education (IE). Therefore, assessing teachers/pre-service teachers' attitudes toward IE with an objective scale is a key issue for many academic publications. This study compared differences in pre-service teachers' attitudes toward IE between Thailand and Japan and discussed these differences mainly from the perspective of differences in their educational systems for children with disabilities. Method: This study's survey utilized a modified version of the Attitude Toward Inclusion Instrument. The study participants were 109 and 221 pre-service teachers who were enrolled in teacher preparation programs in Thailand and Japan, respectively. Result: The basic concepts and ideologies of IE were similarly and widely accepted in both countries. However, Thai pre-service teachers were more likely to strongly perceive that education in special schools would have a negative impact for students with disabilities and that IE would have a positive impact. On the other hand, Japanese preservice teachers had a more negative perception of the feasibility of IE compared to Thai teachers. Discussion: We attributed this result to the difference in the popularity and credibility of special education in the two countries. Japanese pre-service teachers held a more positive attitude toward special education compared to their Thai counterparts. However, this attitude may have caused Japanese pre-service teachers to become more concerned about IE, which could be a barrier to expanding IE in Japan.
\end{abstract}

\section{Keywords}

Inclusive Education, Special Education, Disability, Thailand, Japan 


\section{Introduction}

According to the World Health Organization, there are 93 - 150 million children with disabilities between the ages of 0 and 14 worldwide (World Health Organization (WHO), 2011). Children with disabilities are among the most marginalized and excluded groups, and this population group has remained largely invisible to mainstream society and education officials. In most countries, efforts to provide education or training to disabled children are generally carried out through separate special schools, which usually target specific impairments for intervention. However, this situation began to change after the Salamanca World Conference on Special Needs Education, which endorsed the idea of inclusive education (United Nations Educational, Scientific and Cultural Organization (UNESCO), 1994). The Salamanca Statement argued that regular schools with inclusive orientations were "the most effective means of combating discriminatory attitudes, building an inclusive society, and achieving education for all." It further asserted that such schools "provide an effective education for most children and help to improve the efficiency and, ultimately, the cost-effectiveness of the entire education system."

Furthermore, the United Nations Convention on the Rights of Persons with Disabilities and its Optional Protocol was adopted in 2006. The convention asserted that children with disabilities should be included within general education systems and receive appropriate individual support. All countries should ensure that children with disabilities are allowed to receive quality education in an inclusive environment. The achievement of this goal requires the modification of education systems so that barriers can be removed, reasonable accommodations can be provided, and support services can be created to ensure that children with disabilities are not excluded from mainstream educational opportunities. Each country is struggling to enact inclusive education (IE) programs within the contexts of their respective histories, educational systems, and budgets.

Several studies have shown that classroom teachers can strongly influence the implementation and potential success of inclusive education (Lambe \& Bones, 2006; Mitchell \& Hedge, 2007; Soodak et al., 1998; Watnick \& Sacks, 2006). Previous research has indicated that when teachers hold a negative attitude toward the educational inclusion of students with disabilities, education in an inclusive setting is likely to be unsuccessful (Avramidis et al., 2000; Treder et al., 2000). Teachers' negative attitudes toward IE tend to influence teachers' behaviors when children with disabilities are placed into their classrooms. Therefore, assessing teachers' attitudes toward IE with an objective scale is a key issue for many academic publications. Several studies have tried to explain the reason behind teachers' negative attitudes toward IE. These negative attitudes were explained by a lack of training in special education (Leatherman \& Niemeyer, 2005), a lack of contact with someone with a disability (Avramidis \& Norwich, 2002), and a lower degree of confidence in teaching students with disabilities (Zanandrea \& Rizzo, 1998). However, this study tried to conduct an international comparison for pre- 
service teachers and analyze the difference pre-service teachers' attitudes from the perspective of differences in their educational systems for children with disabilities. As the reason mentioned above may strongly be influenced by the national education system of each country, this study did not focus on teachers' individual attitudes. Instead, it examined the effect of the educational system or general education situation for children with disabilities. Therefore, it involved an international comparison study between Thailand and Japan, which have entirely different educational systems.

Regarding international comparison studies, some previous studies have shown cultural differences in teachers' attitudes across different countries. Leyser et al. (1994) reported that teachers from the United States and Germany showed more positive attitudes toward IE compared to teachers from other countries (for example, Ghana, Taiwan, Israel, and the Philippines) (Leyser et al., 1994). Regarding Thailand and Japan, some articles have reported about teachers/pre-service teachers' attitudes toward IE (Hill \& Sukbunpant, 2013; Sukbunpant et al., 2013; Vibulpatanavong, 2017; Yada \& Savolainen, 2017). However, to date, no comparative study has been conducted regarding Thailand and Japan. With regard to Japan, only one study has explored teacher's attitudes toward IE using an objective scale, and it stated that Japanese teachers' attitudes toward IE tended to be somewhat neutral (Yada \& Savolainen, 2019). This study compared differences in pre-service teachers' attitudes toward IE between Thailand and Japan and discussed these differences from the perspective of differences in their educational systems for children with disabilities.

\section{Methods}

\subsection{Instrument}

This study's survey utilized a modified version of the Attitude Toward Inclusion Instrument (Yates, 1995). This instrument was developed for assessing the attitudes of administrators, special education teachers, and regular education teachers regarding inclusive education for students with disabilities in regular education settings. The original version of the Attitude Toward Inclusion Instrument has 38 items and used a 4-point Likert scale to elicit subject responses (range: 1 [strongly disagree] to 4 [strongly agree]). However, to reduce the time required for completing the survey and apply it to pre-service teachers, we used the 20 items version modified by Swain et al. (2012).

\subsection{Participants and Procedure}

The study participants were 109 and 221 pre-service teachers who were enrolled in teacher preparation programs at Mahasarakham University in Thailand and Gifu University in Japan, respectively. The Japanese subjects included pre-service teachers in the third year of their special education training course. On the other hand, the Thai subjects did not include such pre-service teachers as teachers take extra courses after their placement to study special education in Thailand. The 
duration of the university teacher training course was five years in Thailand and four years in Japan. Both subject groups were surveyed during the teacher preparation program. The questionnaires were distributed to all students of the targeted class and collected during the same session. This survey was conducted between 2019 and 2020 .

\subsection{Translating the Questionnaires}

The whole sections of the instrument were originally written in English. Thai and Japanese authors then translated the instrument into fluent Thai and Japanese, respectively; these authors were also fluent in English. Other Thai or Japanese authors, whose specialty was special needs education, checked the content and quality of the translated content.

\subsection{Ethics and Data Analysis}

This research design was approved by the Ethical Review Committee of the Graduate School of Medicine, Gifu University, in 2018 (approval No. 2018-080). Statistical analysis was performed using JMP ${ }^{\circledR}$ ver. 10.0.2 (SAS Institute, Tokyo, Japan). To compare each item from the Attitude Toward Inclusion Instrument between the Thai and Japanese instrument versions, we used a Student's t-test.

\section{Results}

Table 1 shows the background of the study participants. Compared to the Japanese participant group, the Thai participant group included more women and older subjects. In Japan, the number of pre-service teachers taking the special education training course was $30(12.6 \%)$. Table 2 shows each item from the questionnaire and the respective responses from Thai and Japanese participants.

Table 1. The background of participants in Thailand and Japan.

\begin{tabular}{ccc}
\hline & \multicolumn{2}{c}{ Number of subjects (\%) } \\
\cline { 2 - 3 } Gender & Thailand & Japan \\
Men & $29(26.6 \%)$ & $86(38.9 \%)$ \\
Women & $80(73.4 \%)$ & $134(60.6 \%)$ \\
No reply & $0(0.0 \%)$ & $1(0.5 \%)$ \\
Age & & $1(0.5 \%)$ \\
18 y.o & $0(0.0 \%)$ & $128(57.9 \%)$ \\
19 y.o & $0(0.0 \%)$ & $80(36.2 \%)$ \\
20 y.o & $5(4.6 \%)$ & $11(5.0 \%)$ \\
21 y.o & $21(19.3 \%)$ & $1(0.5 \%)$ \\
more than 21 y.o. & $83(76.2 \%)$ & $221(100.0 \%)$ \\
Total & $109(100.0 \%)$ & \\
\hline
\end{tabular}


Table 2. Questionnaire about IE and the corresponding answers in Thailand and Japan.

\begin{tabular}{|c|c|c|c|c|c|c|c|}
\hline & & \multicolumn{2}{|c|}{ Thailand } & \multicolumn{2}{|c|}{ Japan } & \multirow{2}{*}{$\mathbf{t}$} & \multirow{2}{*}{$p$} \\
\hline & & M & SD & $\mathbf{M}$ & $\mathrm{SD}$ & & \\
\hline 1 & Inclusion is generally a desirable practice. & 3.01 & 0.83 & 3.00 & 0.55 & -0.10 & \\
\hline 2 & Students with disabilities should have the right to be in general classrooms. & 3.28 & 0.82 & 3.25 & 0.62 & -0.40 & \\
\hline 3 & $\begin{array}{l}\text { Given the current structure of the classroom, it is feasible to teach students with disabilities, } \\
\text { students who are gifted, and students without disabilities in the same class with minor } \\
\text { changes within the classroom. }\end{array}$ & 2.96 & 0.79 & 2.67 & 0.68 & -3.37 & 0.0005 \\
\hline 4 & $\begin{array}{l}\text { Support personnel such as special education teachers, speech-language pathologists, and } \\
\text { paraeducators should take their services into a general classroom. }\end{array}$ & 3.41 & 0.64 & 3.05 & 0.58 & -5.06 & $<0.001$ \\
\hline 5 & $\begin{array}{l}\text { Many of the activities teachers do with students without disabilities are also appropriate } \\
\text { for students with disabilities. }\end{array}$ & 2.69 & 0.91 & 2.47 & 0.78 & -2.18 & 0.0152 \\
\hline 6 & The needs of students with disabilities can best be served through special classes. & 3.25 & 0.71 & 2.86 & 0.65 & -4.74 & $<0.001$ \\
\hline 7 & $\begin{array}{l}\text { The opportunity of being in a general education classroom will promote the academic } \\
\text { growth of the student with a disability. }\end{array}$ & 2.17 & 1.00 & 2.89 & 0.69 & 6.75 & $<0.001$ \\
\hline 8 & $\begin{array}{l}\text { The extra attention students with disabilities require will be to the detriment of the other } \\
\text { students. }\end{array}$ & 3.40 & 0.67 & 2.47 & 0.77 & -11.36 & $<0.001$ \\
\hline 9 & $\begin{array}{l}\text { Inclusion offers mixed group interaction, which will foster understanding and acceptance } \\
\text { of the differences in individuals. }\end{array}$ & 3.21 & 0.82 & 3.09 & 0.59 & -1.37 & \\
\hline 10 & Classroom teachers possess the expertise to work with children with disabilities. & 3.00 & 0.82 & 2.54 & 0.75 & -4.92 & $<0.001$ \\
\hline 11 & $\begin{array}{l}\text { Isolation in a special class has a negative effect on the social and emotional development } \\
\text { of students with disabilities. }\end{array}$ & 2.89 & 0.89 & 2.29 & 0.66 & -6.31 & $<0.001$ \\
\hline 12 & Most students with a disability do not make an adequate attempt to complete their tasks. & 2.25 & 0.94 & 2.01 & 0.69 & -2.35 & 0.01 \\
\hline 13 & $\begin{array}{l}\text { Inclusion of students with disabilities will require significant changes in regular } \\
\text { classroom procedures. }\end{array}$ & 3.33 & 0.69 & 2.91 & 0.59 & -5.38 & $<0.001$ \\
\hline 14 & The contact students without disabilities have with students with disabilities may beharmful. & 2.23 & 0.90 & 1.99 & 0.80 & -2.35 & 0.10 \\
\hline 15 & Students with disabilities will likely monopolize the teacher's time. & 2.12 & 0.92 & 2.60 & 0.74 & 4.73 & $<0.001$ \\
\hline 16 & Inclusion of students with disabilities will promote their social independence. & 2.98 & 0.81 & 2.97 & 0.61 & -0.15 & \\
\hline 17 & $\begin{array}{l}\text { Parents of students with disabilities will present more challenges for a teacher than those } \\
\text { of children without disabilities. }\end{array}$ & 2.87 & 0.75 & 2.84 & 0.72 & -0.35 & \\
\hline 18 & $\begin{array}{l}\text { Students with disabilities should be given every opportunity to function in the general } \\
\text { education setting. }\end{array}$ & 3.40 & 0.70 & 2.97 & 0.61 & -5.57 & $<0.001$ \\
\hline 19 & $\begin{array}{l}\text { The inclusion of students with disabilities can be beneficial for students in the general } \\
\text { education setting. }\end{array}$ & 3.21 & 0.69 & 2.97 & 0.55 & -3.19 & 0.00 \\
\hline 20 & $\begin{array}{l}\text { Students with disabilities will probably develop academic skills more rapidly in a special } \\
\text { education classroom. }\end{array}$ & 1.73 & 0.70 & 2.77 & 0.68 & -6.11 & $<0.001$ \\
\hline
\end{tabular}

We found that the basic concepts and ideologies of IE (Q1, Q2, Q9, Q14, Q16) were similarly and widely accepted in both countries. However, Thai pre-service teachers were concerned about a more negative impact from IE on general students (Q8, Q13) compared to the Japanese teachers. Thai pre-service teachers were more likely to strongly perceive that education on special schools would have a negative impact for students with disabilities (Q11, Q20) and that IE would have a positive impact on students with disabilities (Q18, Q19). However, 
Thai pre-service teachers' attitudes were inconsistent. They suggested that being in a general education classroom will (not) promote the academic growth of students with disabilities (Q7) and that the needs of students can be best served through special classes (Q6). On the other hand, Japanese pre-service teachers had a more negative perception of the feasibility of IE compared to Thai teachers-for example, "Classroom teachers (do not) possess the expertise to work with children with disabilities" and "Students with disabilities will likely monopolize the teacher's time” (Q3, Q10, Q15).

\section{Discussion}

This is the first study to use objective scales in both Japan and Thailand to show pre-service teachers' attitudes toward IE. Therefore, it is also the first study to compare pre-service teachers' attitudes toward IE in Thailand and Japan, respectively. We found that attitudes toward IE were neutral and similar in Thailand and Japan. However, looking at some items, concerns about IE took on different viewpoints. In short, pre-service teachers in both countries showed a similar acceptance toward basic IE concepts and ideologies. However, Thai pre-service teachers expressed more concerns about the impact of IE on general students compared to the Japanese pre-service teachers. Furthermore, they were more concerned about any negative impacts of special education on special schools and any positive impacts of IE on students with disabilities. Thus, Thai pre-service teachers were more likely to negatively view special education in special schools, and they considered a better choice despite its negative impact on general students. On the other hand, compared to the Thai pre-service teachers, Japanese pre-service teachers held a more negative impression of the feasibility of IE. It is possible that this attitude resulted from the long history of special education in special schools and the reliability of these schools. A long history of experience in special education may cause more concerns about the feasibility of IE. In other words, such a long period of experience in the special education field may hinder the expansion of IE in Japan. Table 3 shows the number of schools/ classes, students, and teachers within each category.

In Thailand, children with disabilities are educated through one or multiple services: 1) inclusive education in regular schools, 2) special schools, 3) home schools, 4) community/private organizations, 5) hospitals, 6) special education centers, and 7) informal education centers (Vibulpatanavong, 2017). There are currently 48 special schools, which are classified into the following four types of special schools: schools for those with intellectual disabilities, those with hearing impairments, those with visual impairments, and those with physical impairments. Most children with disabilities are accepted into IE schools. There are currently 24,216 IE schools in Thailand, which are all assisted by special schools and centers with regard to teacher training, teaching materials, and management systems. Notably, the Thai government provided extra income (around 100 USD/month) for teachers who accumulated 200 hours of training in the centers 
Table 3. A comparison of the statuses of special schools in Thailand and Japan.

\begin{tabular}{ccc}
\hline & Thailand & Japan \\
\hline Area & 66.6 million & 126.2 million \\
Number of special schools & 513 thousand km² & 380 thousand $\mathrm{km}^{2}$ \\
Number of students in special schools & $48^{\#}$ & 1141 \\
Number of teachers in special schools & 9446 & 143,379 \\
Number of special classes & 3632 & 84,600 \\
Number of students in special classes & 654 & 36,139 \\
Number of teachers in special classes & 12,428 & 256,671 \\
Number of students in partially IE settings & 50,108 & 68,266 \\
\hline
\end{tabular}

${ }^{*}$ Cited from (Special education technology, Thai Search, 2020) and (Special Education Bureau, Thailand Search, 2020) for Thai data and from (Documents of Special Education, Ministry of Education, Culture, Sports, Science and Technology Japan, 2020) for Japanese data. "Thailand has another type of educational institute for children with disabilities: 51 welfare schools and 77 special education centers. These institutes do not have approval to function as schools from the Ministry of Education.

and passed the examination and taught children with disabilities in their classrooms.

Japanese children with disabilities have traditionally been educated in special schools, and they are assigned to visual, hearing, physical, or health impairment schools based on their disabilities. However, the number of students who belong to special classes is increasing these days. These special classes are offered by general schools, but their classes are held separately; furthermore, they accept children with moderate disabilities and, more often, children with developmental disabilities. Some children with mild disabilities are assigned to the "other setting" category-that is, partially IE setting classes. As Table 3 shows, most children are accepted into special schools or special classes. Notably, the Japanese system is extremely costly, especially with regard to the high student-teacher ratio in Japan. That ratio is 1.69 and 3.76 for special schools and special classes, respectively.

To compare the attitudes toward IE across multiple countries, it is essential to consider their differences in terms of education systems for children with disabilities. We believe that previous studies were somewhat lacking in this regard (Hill \& Sukbunpant, 2013; Leyser et al., 1994; Sukbunpant et al., 2013; Vibulpatanavong, 2017; Yada \& Savolainen, 2017, 2019). The current situations and histories of education for children with disabilities are completely different in Thailand and Japan. Therefore, we should interpret the results of this questionnaire with regard to that difference of situation. Despite the large differences in educational systems for children with disabilities in both countries, the basic conception or ideology of IE was similarly accepted in both countries. The only difference was that, unlike Japanese pre-service teachers, Thai pre-service teachers felt that children with disabilities should be accepted into IE settings rather than into 
special schools. We attributed this result to the difference in the popularity and credibility of special education in the two countries. Japanese pre-service teachers held a more positive attitude toward special education compared to their Thai counterparts. However, this attitude may have caused Japanese pre-service teachers to become more concerned about IE, and it could be a barrier to expanding IE in Japan. Thus, this comparative study revealed not only the differences in Japan and Thailand's attitudes toward IE but also where these differences originated. These findings may provide useful knowledge for improving the current situation of educational systems for children with disabilities in both countries. This study compared only the attitudes of pre-service teachers in this study. In future studies, we would recreate the methodology but would choose a participant pool of teachers in the next stage of their careers. We would have a more detailed analysis and could propose a practical implication using the result of this survey.

\section{Conclusion}

The basic concepts and ideologies of IE were similarly accepted in Thailand and Japan. However, Thai pre-service teachers tended to consider IE more positively than special schools. On the other hand, Japanese pre-service teachers held a more negative impression of the feasibility of IE compared to Thai pre-service teachers. The limitation of this study is that the targeted pre-service teachers' age is different in the two countries because of the difference in teacher training systems, which might affect the result. Further, this study was conducted in only one university for each country. Therefore, the professors' attitudes might affect the attitudes of pre-service teachers. However, this study's findings might suggest that the differences in attitudes originated from the differences between the educational systems for children with disabilities in both countries.

\section{Conflicts of Interest}

The authors declare no conflicts of interest regarding the publication of this paper.

\section{References}

Avramidis, E., Bayliss, P., \& Burden, R. (2000). Student Teachers' Attitudes towards the Inclusion of Children with Special Educational Needs in the Ordinary School. Teaching and Teacher Education, 16, 277-293. https://doi.org/10.1016/S0742-051X(99)00062-1

Avramidis, E., \& Norwich, B. (2002). Teachers' Attitudes towards Integration/Inclusion: A Review of the Literature. European Journal of Special Needs Education, 17, 129-147. https://doi.org/10.1080/08856250210129056

Documents of Special Education, Ministry of Education, Culture, Sports, Science and Technology Japan (2020). https://www.mext.go.jp/content/20200428-mxt tokubetu01-000004454.pdf

Hill, D. A., \& Sukbunpant, S. (2013). The Comparison of Special Education between Thailand and the United States: Inclusion and Support for Children with Autism Spec- 
trum Disorder. International Journal of Special Education, 28, 120-134.

Lambe, J., \& Bones, R. (2006). Student Teachers' Perceptions about Inclusive Classroom Teaching in Northern Ireland Prior to Teaching Practice Experience. European Journal of Special Needs Education, 21, 167-186. https://doi.org/10.1080/08856250600600828

Leatherman, J. M., \& Niemeyer, J. A. (2005). Teachers' Attitudes toward Inclusion: Factors Influencing Classroom Practice. Journal of Early Childhood Teacher Education, 26, 23-36. https://doi.org/10.1080/10901020590918979

Leyser, Y., Kapperman, G., \& Keller, R. (1994). Teacher Attitudes toward Mainstreaming: A Cross-Cultural Study in Six Nations. European Journal of Special Needs Education, 9, 1-15. https://doi.org/10.1080/0885625940090101

Mitchell, L. C., \& Hedge, A. V. (2007). Beliefs and Practices of In-Service Preschool Teachers in Inclusive Settings: Implications for Personnel Preparation. Journal of Early Childhood Teacher Education, 28, 353-366.

https://doi.org/10.1080/10901020701686617

Soodak, L. C., Podell, D. M., \& Lehman, L. R. (1998). Teacher, Student, and School Tributes as Predictors of Teachers' Responses to Inclusion. Journal of Special Education, 31, 480-497. https://doi.org/10.1177/002246699803100405

Special Education Bureau, Thailand Search (2020). http://special.obec.go.th

Special Education Technology, Thailand Search (2020). http://203.159.157.29/set index/index.php

Sukbunpant, S., Arthur-Kelly, M., \& Dempsey, I. (2013). Thai Preschool Teachers' Views about Inclusive Education for Young Children with Disabilities. International Journal of Inclusive Education, 17, 1106-1118. https://doi.org/10.1080/13603116.2012.741146

Swain, K. D., Nordness, P. D., \& Leader-Janssen, E. M. (2012). Changes in Preservice Teacher Attitudes toward Inclusion. Preventing School Failure: Alternative Education for Children and Youth, 56, 75-81. https://doi.org/10.1080/1045988X.2011.565386

Treder, D. W., Morse, W. C., \& Ferron, J. M. (2000). The Relationship between Teacher Effectiveness and Teacher Attitudes toward Issues Related to Inclusion. Teacher Education and Special Education: The Journal of the Teacher Education Division of the Council for Exceptional Children, 23, 202-210. https://doi.org/10.1177/088840640002300303

UNESCO (1994). The Salamanca Statement and Framework for Action on Special Needs Education. https://unesdoc.unesco.org/ark:/48223/pf0000098427

Vibulpatanavong, K. (2017). Inclusive Education in Thailand. Advances in Social Science, Education and Humanities Research, 169, 67-70.

Watnick, B., \& Sacks, A. (2006). A Snapshot of Teacher Perceptions on Full Inclusion in an International Urban Community: Miami-Dade County, Florida. The Journal of the International Association of Special Education, 7, 67-74.

WHO (2011). World Report on Disability 2011. http://whqlibdoc.who.int/publications/2011/9789240685215 eng.pdf?ua=1

Yada, A., \& Savolainen, H. (2017). Japanese In-Service Teachers' Attitudes toward Inclusive Education and Self-Efficacy for Inclusive Practices. Teaching and Teacher Education, 64, 222-229. https://doi.org/10.1016/j.tate.2017.02.005

Yada, A., \& Savolainen, H. (2019). Japanese and Finnish Teachers' Perceptions and Self-Efficacy in Inclusive Education. Journal of Research in Special Educational Needs, 19, 60-72. https://doi.org/10.1111/1471-3802.12478

Yates, C. M. (1995). Attitudes of School Personnel in South Mississippi toward Inclusion 
A. Nishio et al.

of Students with Disabilities. Dissertation Abstracts International, 57 (UMI No. 9615286).

Zanandrea, M., \& Rizzo, T. (1988). Attitudes of Undergraduate Physical Education Majors in Brazil toward Teaching Students with Disabilities. Perceptual \& Motor Skills, 86, 699-706. https://doi.org/10.2466/pms.1998.86.2.699 